\title{
Trends, Issues, Best Practices and Current Research in Organizational Training and Performance: an AECT Division of Organizational Training and Performance Special Issue of Tech Trends
}

\author{
Nancy B. Hastings ${ }^{1}$ • Jennifer A. Bauman ${ }^{2}$ \\ Published online: 5 December 2019 \\ (C) Association for Educational Communications \& Technology 2019
}

The most recent AECT-sponsored definition of Educational Technology states "Educational technology is the study and ethical application of theory, research, and best practices to advance knowledge as well as mediate and improve learning and performance through the strategic design, management and implementation of learning and instructional processes and resources" (AECT, 2018). This definition provides us with a precise statement noting what educational technology is (the study and ethical application of theory, research, and best practices), its purpose (to advance knowledge as well as mediate and improve learning and performance), and how it does so (through the strategic design, management, and implementation of learning and instructional processes and resources).

The mission of the AECT Division of Organizational Training and Performance is "to bridge the gap between research and practice, facilitating communication, collaboration and sharing between academics, students, and practitioners across multiple disciplines interested in applying current theory and research to training and performance improvement initiatives" (OTP Bylaws, 2018, p.1). The notable difference between the above definition of educational technology and the division mission statement is that the mission statement also includes where educational technology is researched and practiced; "across multiple disciplines." These three words note the diversity of the field, reminding us that "educational" doesn't necessarily mean K12 classrooms and higher

Nancy B. Hastings

nhastings@uwf.edu

Jennifer A. Bauman

jbauman@gpstrategies.com

1 University of West Florida, Pensacola, FL, USA

2 GP Strategies, Troy, MI, USA education institutions. The need to improve learning and performance and effectively integrate emerging technologies touches all organizations and therefore, so must our research.

The articles included in this special issue reflect the diversity of the field, addressing a broad range of topics related to trends, issues, best practices, and current research in organizational training and performance. Jill Stefaniak opens the issue with "The Utility of Design thinking to Promote Systemic Instructional Design Practices in the Workplace". Susie Gronseth and Holly Hutchins follow with "Flexibility in Formal Workplace Learning: Technology Applications for Engagement Through the Lens of Universal Design for Learning", followed by Alison Moore and James Klein's article titled "Facilitating Informal Learning at Work". Eric Belt and Patrick Lowenthal follow with "Best Practices for Helping Faculty Teach with Technology: A Review of the Literature", which is followed by "Integrating Evidenced-Based Counseling Interventions into Employee Development and Training: A Narrative Discussion on Counseling Professionals and Business Owners Working Together to Better Serve the Employee and Workplace Environment" authored by Melissa McCarthy and David Ford. This article is followed by "Performance Improvement Technology for Building a Sustainable OER Initiative in an Academic Library" authored by Kathy Essmiller, Penny Thompson, and Frances AlvaradoAlbertorio; "Negentropy: Energy Creating Tools for Organizational Change" by Ali Carr-Chellman, Allen Kitchel, and Sydney Freeman; and "Transfer of Training, Trainee Attitudes and Best Practices in Training Design: A MultipleCase Study" by Mohan Yang, Victoria Lowell, Ahmad Talafha, and Jonathan Harbor. The special issue closes with "Development and Implementation of a Maturity Model of Digital Transformation" by Dirk Ifenthaler and Marc Egloffstein, "Designing Microlearning Instruction for Professional Development through a Competency Based Approach" by Jiahui Zhang and Richard West, "Serious 
Games and Gamification in the Corporate Training Environment: A Literature Review" by Kristi Larson, and finally "A Case Study for the 10-Step Approach to Program Evaluation" authored by Suzanne Ensmann, Angela Ward, Andrea Fonseca, and Erika Petersen.

The common theme linking these highly diverse articles together is that they address the application of educational technology in organizational training and performance. They are indicative of the many disciplines impacted by the field and illustrative of the importance of expanding our efforts beyond traditional educational settings to "advance knowledge as well as mediate and improve learning and performance" (AECT, 2018) across all sectors. It is our hope that these articles will inspire readers to expand their vision, considering the many arenas in which educational technology is practiced and the importance of bridging the gap between research and practice. 